\title{
An Improved Thermal Performance Modeling for High-speed Spindle of Machine Tool Based on Thermal Contact Resistance Analysis
}

\section{Bing Fang}

College of Mechanical and Electrical Engineering, Fujian Agriculture and Forestry University

\section{Mengna Cheng}

College of Mechanical and Electrical Engineering, Fujian Agriculture and Forestry University

Tianqi Gu ( $\sim$ gutianqi2011@126.com )

Fuzhou University

\section{Dapeng Ye}

College of Mechanical and Electrical Engineering, Fujian Agriculture and Forestry University

\section{Research Article}

Keywords: spindle, thermal contact resistance, interface, elastoplastic contact, thermal performance

Posted Date: August 30th, 2021

DOI: https://doi.org/10.21203/rs.3.rs-845253/v1

License: (c) (i) This work is licensed under a Creative Commons Attribution 4.0 International License. Read Full License 


\title{
An improved thermal performance modeling for high-speed spindle of machine tool based on thermal contact resistance analysis
}

\author{
Bing Fang ${ }^{1}$, Mengna Cheng ${ }^{1}$, Tianqi Gu²*, Dapeng $\mathrm{Ye}^{1}$ \\ (1. College of Mechanical and Electrical Engineering, Fujian Agriculture and Forestry University, Fuzhou 350002, \\ China; 2. College of Mechanical Engineering and Automation, Fuzhou University, Fuzhou, 350108, China) \\ *Corresponding author e-mail: gutianqi2011@126.com
}

\begin{abstract}
The distribution of the temperature field has a great influence on structural performance, thermal deformation, thermal error compensation. To improve the prediction accuracy of the temperature distribution of the spindle system, a comprehensive model considering the contact thermal resistance (TCR) of the interfaces was established to analyze the thermal performance of high-speed spindle system in the present work. An elastoplastic contact model was used to calculate the contacting areas and loads of interfaces, which were employed to establish the contact thermal resistance model of the main interfaces of spindle, such as bearing rings and tool holders. Basing on the TCR parameters, a Finite Element Analysis (FEA) model was proposed to analyze the temperature distribution of the spindle system. And a temperature test experiment was set up to verify the accuracy of the FEA model. The results show that the relative error of representative test points was all less than $5 \%$, which means the established model can appropriately reflect the temperature field distribution of the spindle.
\end{abstract}

Keywords: spindle, thermal contact resistance, interface, elastoplastic contact, thermal performance

\section{Introduction}

As the core functional component of precision machine tools, the high-speed spindle system is crucial for the implementation of high-speed and high-accuracy machining [1,2]. However, with the improvement of running speed, the influence of vibration and thermal becomes more and more significant. Especially, the error generated by thermal deformation. It is shown that errors induced by heat account for nearly $40 \%-70 \%$ of the total error of a precision machine tool [3]. Therefore, it is important to study how the heat influences the accuracy of the machine tools.

Usually, a thermal-mechanical coupling model is used to analyze the temperature distribution and deformation of main parts of machine tools. Those models can be used both in the design and working stage. During the design stage, the thermal-mechanical model can be used to predict the deformation of the error of spindle tools under the action of 
specific condition [4-6]. Those models can also be used for the thermal error compensation $[7,8]$ and thermal error control techniques $[9,10]$ in working stage. The distribution of temperature is the foundation of thermal-mechanical coupling model. There are usually two foundation methods to solve the temperature field, the thermal grid method [11-13] and the finite element method [14-16].

For the situation of high-spindle system, heat generated by the friction of bearing and built-in motor flowed through parts causing linear and nonlinear thermal expansions, which distorts associated structures and produce deformations. What is more, spindle system is complicated system composed of many components with many kinds of interfaces. Their thermal and mechanical behaviors are not only determined by these components but also by the characteristics of various interfaces [17]. When the heat flowing contact areas, such as interfaces between the bearing and the shaft, the bearing and the bearing support, and the ball screw and nut, the thermal changing are always nonlinear and produces nonlinear thermal deformations, which adversely affect the stiffness of interfaces [18]. Therefore, the thermal positioning error and contact interface on the interface is one of the most important objects to consider for the design of machine tools.

To acquire the value of TCR, both the theorical and experimental method are used. Compare with the experimental method [19, 20], the theorical methods [21-23] got more scholars' attention because of a wider applicability. There are three key parameters to calculate the TCR: distribution of pressure, really contact area and thickness of contact region. All those parameters and their relationship can be deduced by the rough surfaces contact theories. For a given load condition, the real contact area and the displacement approach amount can be confirmed by the statistics-based method $[24,25]$ or fractal-based method [26, 27], and then get the value of TCR. So, the contact models determine the validity and convenience of TCR calculation. No matter which method was used, the basic work is to deal with the contact problem between a single asperity and a flat rigid surface. Three-stage contact models, which are elastic, Elastoplastic, and plastic stage, are now wildly used [28, 29].

Basing on an advanced contact method, which analyze the relationship between real area and deformation of contacted rough surfaces under the specific load, a comprehensive model for thermal study was proposed in the present work. Together with thermal boundary condition, such as the heat generating and thermal convection, the proposed model took three kinds of typical interfaces (bolt joints, ring joints and tapered joint) into account. The TCR of those interfaces were acquired according to the distribution of pressure of joints under different loaded characteristics. And experiments were carried out on a vertical machine center for a period of 5.5 hour running and 1.5 hours stopping to verify the proposed thermo-mechanical model by comparing the temperature and thermal error data. 


\section{Theory background}

\section{1 rough surface contact model}

The contact of two rough surfaces can be simplified as a rough surface in contact with a rigid plane. Basing on the Hertz contact theory and statistical method, GREENWOOD proposed a contact analysis model, named as GW model, which assumed that the height of asperities obeyed a certain distribution (usually Gaussian distribution) and that asperities had the same radius of curvature [30]. The deformation for a single asperity experienced elastic or plastic stage in this model. However, researchers believed that there was a transitional phase between those two stages. Through the method of finite element analysis, KOUGT discovered that the asperity undergoes an elastic-plastic mixed deformation stage before it began to enter the plastic deformation stage [31]. In the present work, the contact behavior of asperities would be divided into three stages: elasticity, elastoplastic and plasticity.

\subsection{1 elastic deformation}

According to the Hertz contact theory, the relationship between the elastic contact area $a_{e}$, the elastic contact load $p_{e}$ and the deformation $\omega$ can be established as

$$
\begin{aligned}
& a_{e}=\pi R \omega \\
& p_{e}=\frac{4}{3} E^{*} R^{1 / 2} \omega^{3 / 2}
\end{aligned}
$$

where, $\frac{1}{E^{*}}=\frac{1-v_{1}^{2}}{E_{1}}+\frac{1-v_{2}^{2}}{E_{2}}$

$E_{1}, E_{2}$ are the shear modulus of the material of contact surfaces.

$v_{1}, v_{2}$ are the Poisson's ratio of the material.

$R$ is the average radius of all asperities.

\subsection{2 totally plastic deformation}

When the average contact pressure of the contacted surface exceeds the hardness of the material, the asperity is in the stage of complete plastic deformation. And the contact area $a_{p}$ and the load $P_{p}$ can be expressed as

$$
\begin{aligned}
& a_{p}=2 \pi R \omega \\
& p_{p}=H a_{p}
\end{aligned}
$$

where, $H$ is the hardness of the softer material in the two contact surfaces.

\subsection{3 elastoplastic deformation}

When the deformation is bigger than critical elastic deformation $\omega_{e}$, as shown in $E q$. (5), the asperity is in the begin 
stage of elastoplastic mixing deformation.

$$
\omega_{e}=\left(\frac{\pi k_{\mu} H}{2 E^{*}}\right)^{2} R
$$

Where, $k_{\mu}$ is the average contact pressure coefficient [32], related to Poisson's ratio of softer materials $v$, and $k_{\mu}=$ $0.4645+0.3141 v+0.1943 v^{2}$

Similar with ZMC model [33], the contact area is expressed as a polynomial expression with the deformation $\omega$ as the independent variable. And that is

$$
a_{e p}=a_{1}\left(\frac{\omega-\omega_{e}}{\omega_{p}-\omega_{e}}\right)^{3}+a_{2}\left(\frac{\omega-\omega_{e}}{\omega_{p}-\omega_{e}}\right)^{2}+a_{3} \frac{\omega-\omega_{e}}{\omega_{p}-\omega_{e}}+a_{4}
$$

To satisfy the continuous condition, the following boundary conditions should be followed.

When $\omega=\omega_{e}$

$$
a_{e p}=a_{e}, \quad \frac{\mathrm{d} a_{e p}}{\mathrm{~d} \omega}=\frac{\mathrm{d} a_{e}}{\mathrm{~d} \omega}
$$

When $\omega=\omega_{p}$

$$
a_{e p}=a_{p}, \quad \frac{\mathrm{d} a_{e p}}{\mathrm{~d} \omega}=\frac{\mathrm{d} a_{p}}{\mathrm{~d} \omega}
$$

According to the above boundary conditions, the polynomial expression for $a_{e p}$ can be constructed as the function of the independent variable $\omega$. And that is

$$
a_{e p}=\pi R \kappa_{1}(\omega)
$$

here, $\kappa_{1}(\omega)=(3-2 \omega) g^{3}(\omega)+(3 \omega-4) g^{2}(\omega)+g(\omega)+\omega$

$$
g(\omega)=\frac{\omega-\omega_{e}}{\omega_{p}-\omega_{e}}
$$

Similarly, the contact load in this period $p_{e p}$ can also be express as the function of $\omega$

$$
p_{e p}=\pi R H\left[1-\left(1-k_{\mu}\right) \frac{\ln \omega_{p}-\ln \omega}{\ln \omega_{p}-\ln \omega_{e}}\right] \kappa_{1}(\omega)
$$

\section{2 average contact pressure of interfaces}

The real contact area is often determined by the contact pressure. Different methods should be taken to deal with different types of contact surfaces. The contact pressure of the bolted joints can be obtained by dividing the given bolt preload by the nominal contact area, which can be easily acquired from the geometrical dimensions. Another 
two types of joint, spindle-handle and shaft-ring, with different load condition should be processed, respectively.

\subsection{1 the interference fit contact pressure}

As shown in Fig.1, the contact pressure of the joint surface of the interference fit, such as shaft and inner rings of bearing, is determined by the interference.

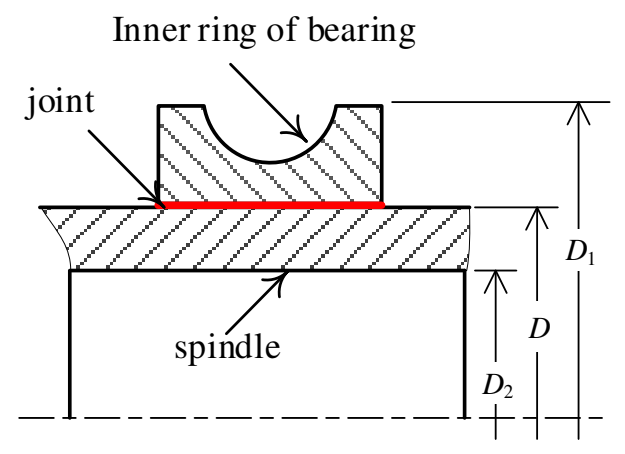

Fig. 1 the joint between shaft and inner rings of bearing

The average contact pressure could be calculated according to the following formula

$$
P_{e x}=\frac{\frac{\Delta}{D}}{\frac{1}{E_{1}}\left[\frac{\left(\frac{D_{1}}{D}\right)^{2}+1}{\left(\frac{D_{1}}{D}\right)^{2}-1}+\mu_{1}\right]+\frac{1}{E_{2}}\left[\frac{\left(\frac{D}{D_{3}}\right)^{2}+1}{\left(\frac{D}{D_{3}}\right)^{2}-1}-\mu_{2}\right]}
$$

where $E_{1}, E_{2}$ are the modulus of the material of rings; $\Delta$ denotes the interference fit; $\mu_{1}$ and $\mu_{2}$ denote the Poisson's ratio of the bearing inner ring and shaft journal, respectively; $D$ denotes the contact diameter; $D_{3}$ denotes the inner diameter of the shaft journal; and $D_{1}$ denotes the outer diameter of the bearing inner ring.

\subsection{2 the spindle holder contact pressure}

The joint surface of the spindle shank is a tapered shape, and the contact load is determined by the broach force. As shown in Fig.2, under the action of axial broach force $F_{p}$, the force balance equation of the shank with taper $\theta$ is

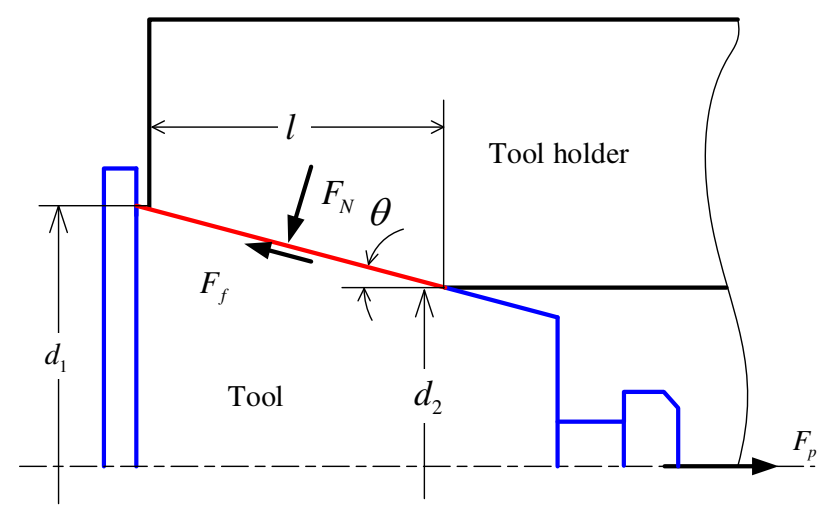

Fig.2 the joint between spindle and holder 


$$
F_{p}=F_{N} \sin \theta+F_{f} \cos \theta
$$

where, $N$ is the normal pressure of contact surface, and $F_{f}$ is the friction force between spindle and shank, respectively. According to the relationship of normal pressure and friction, the above equation can be rewritten as

$$
F_{p}=F_{N}(\sin \theta+\mu \cos \theta)
$$

where, $\mu$ is the coefficient of friction. For the most cases, this coefficient can be assumed to be in the range of 0.12 to 0.2 .

So, the average surface pressure of the cone is

$$
F_{N}=\frac{F_{p}}{\sin \theta+\mu \cos \theta}
$$

\section{3 contact thermal resistances}

As shown in Fig.3, actual contact surfaces are always point-contact or an uneven small area contact. Compared with perfect contact surfaces, there is an additional thermal resistance during the heat conduction process, which is the contact thermal resistance (TCR) [34]. TCR is related to the actual contact state and can be calculated based on contact theory.

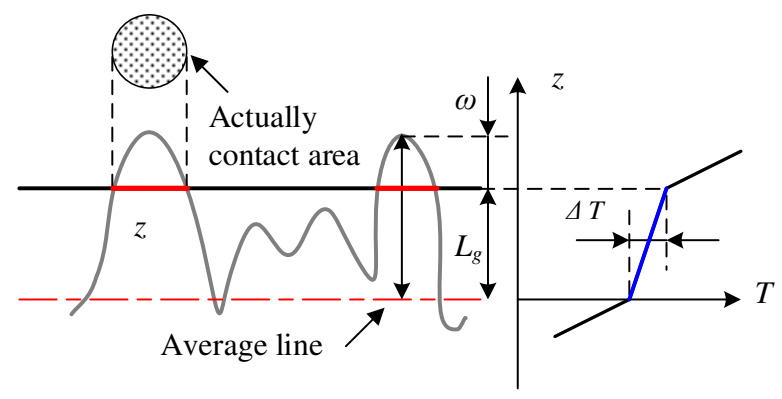

Fig.3 TCR of contacted surfaces

TCR is fundamentally decided by heat transfer coefficient, height of gap and really contact area, which can be formulated as

$$
R_{C}=\frac{L_{\delta}}{k_{s} A_{r}}
$$

where, $L_{\delta}$ and $A_{r}$ are related to contact conditions (such as material, pressure, and roughness), and can be calculated by rough surfaces contact theories.

To simplify the analysis, the thermal contact conductance (TCC), which was the reciprocal the of TCR, was used to calculate the TCR of the interfaces.

For a single asperity, $L_{\delta}$ is the distance from smooth rigid plane to average reference plane, and $A_{r}$ is the hertz contact 
area. So, the TCC of a single micro-contact asperity in different contact situations will be

$$
h_{e}=\left\{\begin{array}{cc}
\frac{\pi k_{s} R \omega}{z-\omega} & \omega<\omega_{e} \\
\frac{\pi k_{s} R \kappa_{1}(\omega)}{z-\omega} & \omega_{e}<\omega<\omega_{p} \\
\frac{2 \pi k_{s} R \omega}{z-\omega} & \omega_{p}<\omega
\end{array}\right.
$$

where, $z$ is the height of the asperity relative to the average line.

According to section 2.2, the total TCC of the whole joint $H_{e}$ can be calculated by

$$
H_{e}(d)=\int_{d}^{d+\omega_{e}} \frac{\pi k_{s} R(z-d)}{d} \phi(z) d z+\int_{d+\omega_{e}}^{d+\omega_{p}} \frac{\pi k_{s} R \kappa_{1}(d)(z-d)}{d} \phi(z) d z+\int_{d+\omega_{p}}^{\infty} \frac{2 \pi k_{s} R(z-d)}{d} \phi(z) d z
$$

\section{FEA model}

\section{1 geometric model}

The thermal performance of spindle system was analyzed by the finite element software ANSYS Workbench. As shown in Fig.4, substructures such as spindle, box, test mandrel and bearings were built and assembled in this software. The spindle was supported by two pairs of bearings mounted on the spindle box, and bearings were arranged by the way that the front had three rows and the rear two rows. The test mandrel was fastened to the holder by pulling force provided by disc-spring. Hex dominant method was used to mesh geometries, and the number of the nodes and elements were 85313 and 25788 respectively.

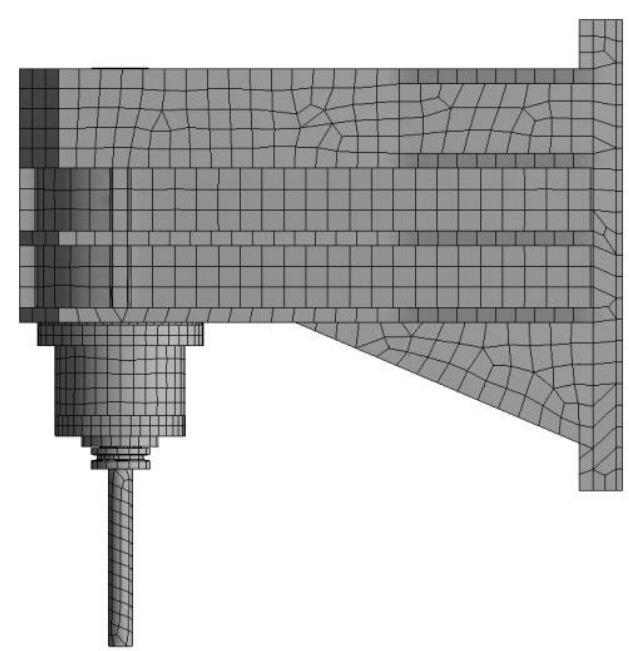

Fig.4 the FEA model of spindle

The connection between prats of the spindle system was defined by contact pair in ANSYS Workbench. The TCR of interfaces can be represented by the parameter " $\mathrm{H}$ " in this item. There were totally three kinds of interfaces: plane joints, bearing joints, and spindle-holder joint. The bearing joints included two types: one was the joint between inner 
ring and shaft, and another was the joint between outer ring and box. The major materials were shown in Tab.1.

Tab.1 Properties of steel cast iron and invar

\begin{tabular}{lccccc}
\hline & Invar & $45 \#$ steel & HT300 & Air & Unit \\
\hline Modulus of elasticity & 145000 & 209000 & 130000 & - & Mpa \\
Poisson's ratio & 0.3 & 0.269 & 0.26 & - & - \\
Coefficient of linear expansion & $1.2 \times 10^{-6}$ & $1.159 \times 10^{-5}$ & $1.1 \times 10^{-5}$ & - & $1 / \mathrm{K}$ \\
Conductivity (k) & 15 & 49.8 & 45 & $2.554 \times 10^{-2}$ & $\mathrm{~W} / \mathrm{mk}$ \\
Specific heat capacity & 525 & 486 & 510 & 1.0069 & $\mathrm{~J} / \mathrm{KgK}$ \\
Density & 8200 & 7824 & 7300 & 1.1769 & $\mathrm{Kg} / \mathrm{mm}$ \\
\hline
\end{tabular}

\section{2 heat generation of bearings}

The major heat generation of the system was caused by the cutting process and the friction between balls and races of the bearings [35]. Assumed that the majority of cutting heat was taken away by coolant and chips, and the heat generated by bearings was the dominant cause of temperature changing.

The heat generated by a bearing can be computed as

$$
H_{f}=1.047 \times 10^{-4} n M
$$

where $H_{f}$ is the heat generated power $(W), n$ is the rotating speed of the bearing (rpm), $M$ is the total frictional torque of the bearing (N.mm). The total frictional torque $M$ consists of two parts. One is the torque $M_{1}$ due to applied load and the other one is the torque $M_{2}$ due to viscosity of lubricant.

And,

$$
M_{1}=f_{1} p_{1} d_{m}
$$

Here, $f_{1}$ is a factor related to the bearing type and load, $p_{1}$ is the bearing preload $(N)$, and $d_{m}$ is the mean diameter of the bearing $(\mathrm{mm})$.

$$
M_{2}=\left\{\begin{array}{cc}
10^{-7} f_{0}(v n)^{2 / 3} d_{m}^{3} & v n \geq 2000 \\
160 \times 10^{-7} f_{0} d_{m}^{3} & v n<2000
\end{array}\right.
$$

Here, $f_{0}$ is a factor related to bearing type and lubrication method, and $v_{0}$ is the kinematic viscosity of the lubricant.

\section{3 thermal convection coefficient}

Rotating parts exposed to the air, such as the spindle, the taper shank, and the test rod, caused the air near those parts to be wound, thereby causing forced convection heat exchange. The calculation between the rotating body and the air using the Nuer Shelter equation [36]. The heat transfer coefficient for convection $h$ is defined as 


$$
h=\frac{N_{u a} \lambda_{a}}{d}
$$

Here, $\lambda_{a}$ is the thermal conductivity of the ambient air; $N_{u \text { a }}$ is the Nusselt number; $d$ is the equivalent diameter of the cylinder.

$N_{u \text { a }}$ was computed from the Reynolds number $R_{e}$, and the Prandtl number $P_{r}$, based on different convection conditions. For this research, the following equation is used

$$
N_{u a}=0.1333 R_{e}^{2 / 3} P_{r}^{1 / 3}
$$

and,

$$
R_{e}=\frac{\omega d^{2}}{v_{f}}
$$

where, $\omega$ is the angular velocity of the rotating body, and $v_{f}$ the kinematic viscosity of the air.

The thermophysical properties of dry air at $20^{\circ} \mathrm{C}$ were as follows: $\lambda_{\text {air }}=0.0259 \mathrm{~W} /(\mathrm{m} \cdot \mathrm{K}), v_{f}=15.06^{*} 10^{-6} \mathrm{~m}^{2} / \mathrm{s}, \mathrm{Pr}_{\text {air }}$ $=0.703$. For free convection around stationary surfaces, the heat transfer coefficient for convection $h=9.7 \mathrm{~W} /\left(\mathrm{m}^{2} \mathrm{~K}\right)$ was used in this paper.

From the above data combined with the size of the rotating shaft of the machine tool spindle, and the heat transfer coefficient of the inner and outer surfaces of the rotating body at each experimental speed can be obtained as shown in Tab.2.

Tab.2 Thermal boundary conditions under different spindle speed

\begin{tabular}{lccc}
\hline Items & $3000 \mathrm{rpm}$ & $4500 \mathrm{rpm}$ & $6000 \mathrm{rpm}$ \\
\hline Heat generation of front bearing $(W)$ & 137.2 & 165.4 & 189.5 \\
Heat generation of rear bearing $(W)$ & 85.9 & 100.6 & 119.2 \\
Convective coefficient of ambient air $\left(W /\left(\mathrm{m}^{2} \cdot K\right)\right.$ & 9.7 & 9.7 & 9.7 \\
Convective coefficient of Spindle surfaces $\left(W /\left(\mathrm{m}^{2} \cdot \mathrm{K}\right)\right.$ & 139.4 & 152.5 & 171.0 \\
Convective coefficient of Mandrel surfaces $\left(W /\left(\mathrm{m}^{2} \cdot \mathrm{K}\right)\right.$ & 87.9 & 101.8 & 135.7 \\
TCR of bearing inner ring/shaft journal $\left(\left(\mathrm{m}^{2} \cdot \mathrm{K} / \mathrm{W}\right)\right.$ & & $8.238^{*} 10-3$ & \\
TCR of bearing outer ring/bearing housing $\left(\left(\mathrm{m}^{2} \cdot \mathrm{K} / \mathrm{W}\right)\right.$ & & $4.238^{*} 10-4$ & \\
TCR of spindle/tool interface $\left(\left(\mathrm{m}^{2} \cdot \mathrm{K} / \mathrm{W}\right)\right.$ & & $1.238^{*} 10-4$ & \\
\hline
\end{tabular}

\section{Result and discussion}

\subsection{FEA result}

According to the thermal boundary conditions given by section 3 , the transient temperature field distribution of the spindle, bearing and spindle box were obtained by the established FEA model. There were totally two stages in this 
procedure. In the first stage, which lasted for 5.5 hours, the spindle was running, and the heat generated by bearings flowed to other parts. What's more, forced convection occurred on the surfaces of rotating parts, such as the node of the spindle and the test mandrel. The second stage lasted for 1.5 hours to simulate the natural heat dissipation process after the spindle stopped. At this stage, surfaces had a natural heat transfer, and there was no heat source anymore. The temperature distribution after the spindle speed was operated at $6000 \mathrm{r} / \mathrm{min}$ for 5.5 hours (at the end of stage I) was shown in Fig. 5(b). It can be seen that the parts with obvious temperature rising were mainly concentrated in the region of the two sets of bearings, and the temperature in the region away from the bearing was nearly unchanged because of the heat source passing for some time.
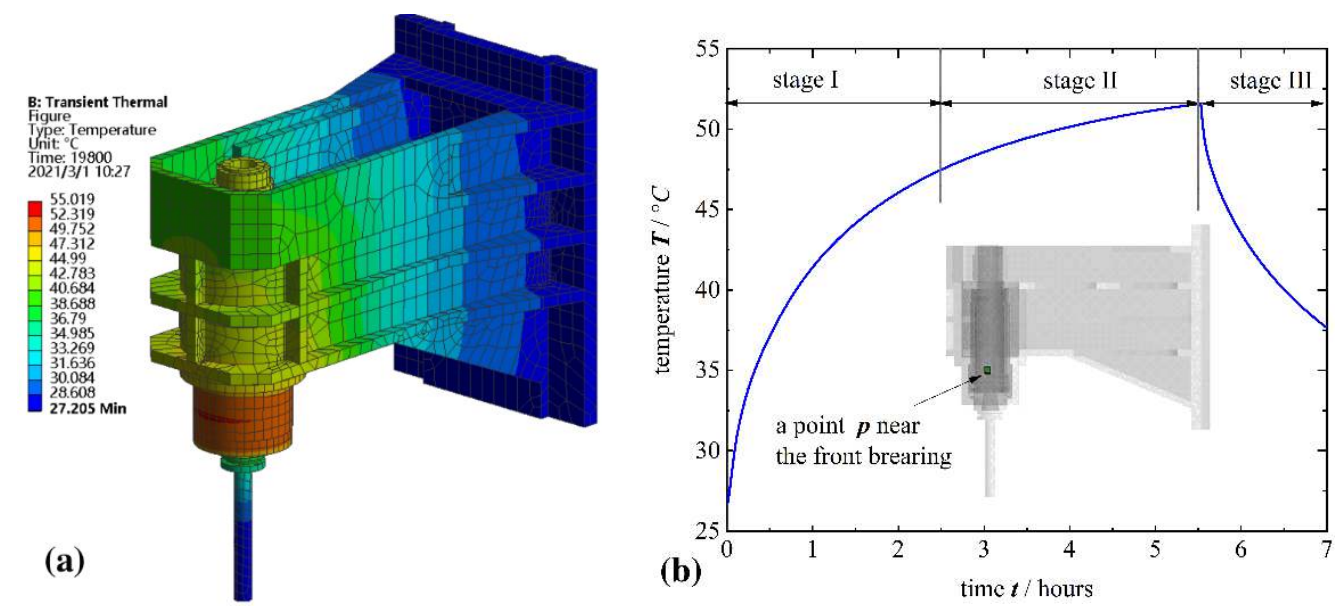

Fig.5 The distribution of temperature field of spindle by simulation (a) spindle and box (b) a given point temperature

The bearing friction was the main heat source of the spindle system, and the internal heat dissipation was difficult. So, the temperature rising was most obvious near bearings. Specifically, the temperature of the spindle nearing the front bearing group was up to $55^{\circ} \mathrm{C}$, and the temperature of the spindle nearing the rear bearing group was nearly to $48^{\circ} \mathrm{C}$. The total temperature rising of the front and rear bearing sets was $27.04{ }^{\circ} \mathrm{C}$ and $21.56^{\circ} \mathrm{C}$, respectively. Although the test mandrel was not far away the front bearings, the temperature hardly increased. Because surfaces exposed to the outside had natural heat exchange or forced convection with the surrounding air, the heat from bearings was then dissipated into surroundings immediately. So, the temperature rise was relatively small.

Fig.5 (b) showed the temperature variation of a small region near the front bearing. From the variations of the temperature-time curves, it was obvious that there were three period throughout the time frame, which were marked as I, II and III, respectively. The temperature increased rapidly during period I, and the temperature of this point raised by nearly $24{ }^{\circ} \mathrm{C}$. In the period II, the temperature changed slowly lasting nearly 3 hours until the spindle stopped, which indicated that the system tended to reach thermal equilibrium; In the period III, the temperature began to decrease, and the rate of decline was faster than later. 


\section{2 experiment result}

Fig.6 showed the experimental measuring scheme and equipment of the spindle system. The transient temperature field of the spindle was measured by 18 thermocouples and a set of data acquisition system. During the experimental procedure, the thermocouples were attached to the stationary surface of the spindle head, and the spindle was ran for 5.5hours, then stopped and cooled for 1.5 hours. During the whole process, the temperature data of thermocouples were collected every $10 \mathrm{~s}$.
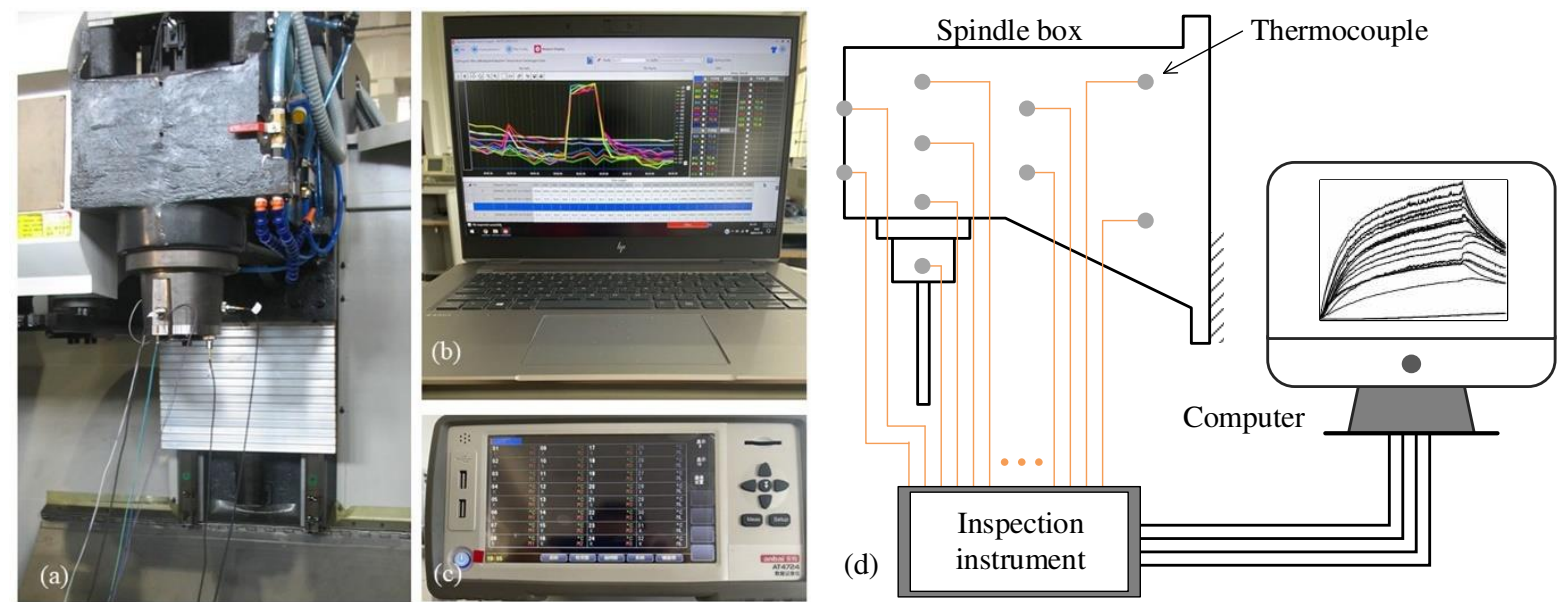

Fig.6 the experimental measuring system for the distribution of temperature field of spindle (a) spindle and box (b) data acquire software (c) Temperature inspection instrument (d) Schematic diagram of test system

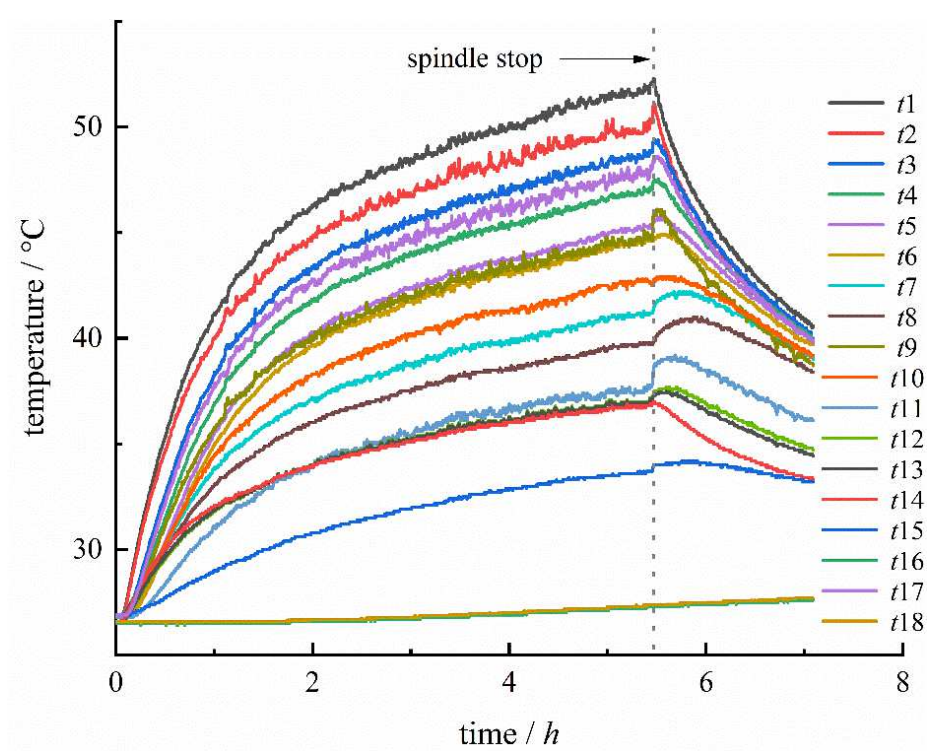

Fig.7 Temperature field of spindle by experiment

Fig. 7 showed the variation of temperature over time, which presented a nonlinear relationship. In the first period, the temperature began to rise immediately, and then its rise began to slow until tended to thermal balance in the second period. The temperature of the whole system was same as ambience before the machine worked, and the heat generated by bearing conducted to other parts resulting the temperature rising once the machine tools working. As 
the increasing of the temperature, the conduction of heat was getting slower due to the change of temperature gradient. In the third period, the temperature began decrease until the ambient temperature overall. That was because the bearings no longer heat up and air convection continued in the outside surfaces. However, several abnormal phenomena were also observed. The temperature of some sensors had a slight rise and then started to fall. At the moment of spindle stopping working, the temperature of inner parts was higher than that of the surfaces exposed to the air, which means there were existence of uneven temperature field, and the heat continued flowing to the outside surfaces. What's more, the situation was not the same for all the 18 sensors. For example, as nearing bearings, T1 T4 had higher temperature than other sensors. The sensors away from the heat generation site, such as $t 17$ and $t 18$, had lower temperature.

\section{3 result and compare}

To verify the simulation results, the experimental data of the spindle was compared with the corresponding position simulation temperature data, and the result was shown in Fig.8. The simulation results were basically consistent with the trend of the experimental results. The maximum relative error of the numerical value was $3.91 \%$ at the time of the spindle stop. Fig. 8 showed the comparison between experimental and theoretical predicted temperatures in steady states.
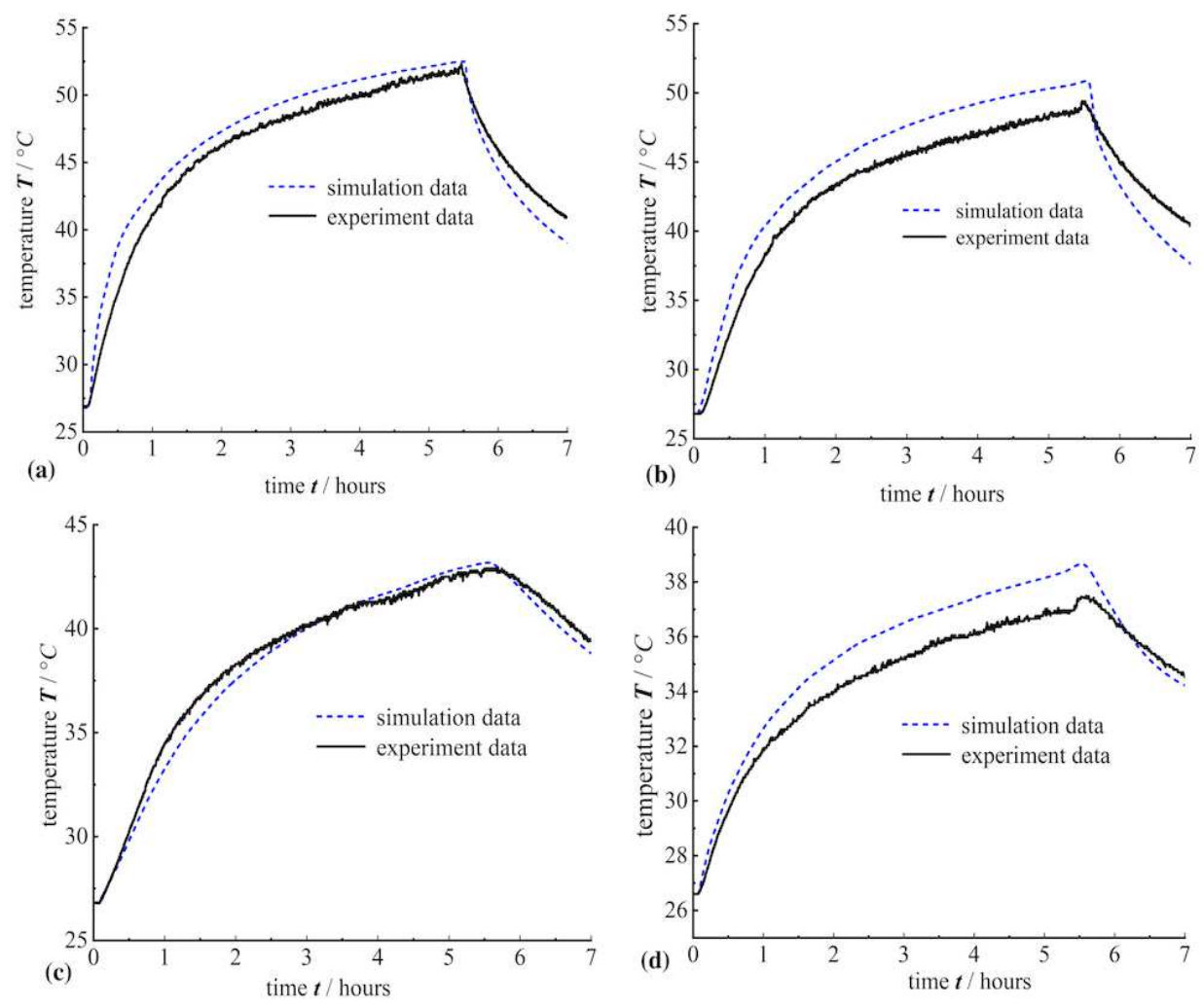

Fig.8 Comparison between the situational value and experimental data (a) test point \#1; (b) test point \#3; (c) test point \#11; (d) test point \#11 
The four observation points with different temperature rising at the front end of the spindle box were compared with the data from the simulation analysis at the corresponding position. The results were shown in Tab.3. From the comparison results, it can be seen that the initial temperature was set to the ambient temperature $\left(26.8^{\circ} \mathrm{C}\right)$, after 5.5 hours of operation, the temperature increased, the absolute difference between simulation and experiment was within $3{ }^{\circ} \mathrm{C}$, and the relative error was within $5 \%$.

Tab.3 Comparison of the simulation and experiment results of the temperature data

\begin{tabular}{|c|c|c|c|c|c|c|c|c|c|c|}
\hline \multirow{2}{*}{$\begin{array}{l}\text { test } \\
\text { point }\end{array}$} & \multicolumn{2}{|c|}{ Experiment $\left({ }^{\circ} \mathrm{C}\right)$} & \multicolumn{4}{|c|}{ simulation with $\operatorname{TCR}\left({ }^{\circ} \mathrm{C}\right)$} & \multicolumn{4}{|c|}{ simulation without $\mathrm{TCR}\left({ }^{\circ} \mathrm{c}\right)$} \\
\hline & $T_{\text {stop }}$ & $T_{\text {final }}$ & $T_{\text {stop }}$ & error & $T_{\text {final }}$ & error & $T_{\text {stop }}$ & Error & $T_{\text {final }}$ & error \\
\hline$\# 1$ & 51.3 & 40.6 & 52.49 & $2.3 \%$ & 38.35 & $-5.5 \%$ & 54.17 & $5.6 \%$ & 39.65 & $-2.3 \%$ \\
\hline$\# 3$ & 49.4 & 40 & 50.6 & $2.4 \%$ & 37.32 & $-6.7 \%$ & 52.62 & $6.5 \%$ & 38.07 & $-4.8 \%$ \\
\hline$\# 10$ & 42.9 & 39.2 & 43.17 & $0.6 \%$ & 38.6 & $-1.5 \%$ & 45.76 & $6.7 \%$ & 40.61 & $3.6 \%$ \\
\hline \#11 & 37.5 & 34.42 & 38.64 & $3.0 \%$ & 34.2 & $-0.6 \%$ & 41.11 & $9.6 \%$ & 36.83 & $7.0 \%$ \\
\hline
\end{tabular}

\section{Conclusion}

An FEA method to analyze the thermal performance of the spindle system, which considered the effect of major joints, was proposed based on the elastoplastic mixed contact model. The model can be used to accurately predict the temperature distribution of spindle at the design stage without making prototypes, which was very useful for speeding up product development. The validity of the modeling method was verified by experiments. Based on the results and analysis, the following conclusions were obtained.

(1) Basing on the elastic, elastoplastic, and plastic contact model, the TCR of a single point was analyzed by theoretical method. According to the surface topography and contact load, the mean TCR of main interfaces were calculated. The result shown that the value of TCR was mainly affected by real contact area of rough surfaces. So, the contact algorithm of rough surfaces was crucial for calculating TCR.

(2) An improved simulating model was proposed to analyze the temperature distribution of spindle box. In addition to considering the thermal convection conditions and heat generation of bearing, the proposed model focused on the influence of the main interfaces' TCR. The result showed that the temperature changed quickly at the beginning, then the temperature will gradually achieve balance.

(3) To verify the accuracy of the proposed model, an experiment was carried out to measure the temperature variety when the spindle was running. The comparing results showed that the relative error of the proposed model was below $5 \%$ for the spindle stopping temperature. Meanwhile, the relative error of the model without considering the influence 
of TCR was $9.6 \%$. The comparing results confirmed the accuracy of the proposed model.

\section{Acknowledgement}

This research was supported by National Natural Science Foundation of China (Grant No. 51605091 and 51605094), the National Natural Science Foundation of Fujian Province (Grant No. 2017J05073), and Regional Development Project of Fujian Province (Grant No. 2020H4028). The authors gratefully acknowledge financial support provided by the Science and Technology Innovation Special Fund of Fujian Agriculture and Forestry University and Longyan Yifeng Mechanical Science and Technology Co., Ltd.

\section{Authors' contributions}

Fang Bing conceptualized the idea, designed the methodology, and undertook data curation, investigation, formal analysis, project administration, manuscript writing, reviewing, and editing; Gu. Tianqi undertook writing, original draft, review, and editing; Chen Mengna and Ye Dapeng undertook experiment, data curation and investigation and acquired resources.

\section{Declarations}

Consent to participate and publish: The authors declare that they participated in this paper willingly and the authors declare to consent to the publication of this paper.

Competing interests: The authors declare that there is no conflict of interest.

\section{Reference}

1. Aalilija A, Gandin C-A, Hachem E (2021). A simple and efficient numerical model for thermal contact resistance based on diffuse interface immersed boundary method. International Journal of Thermal Sciences. 166: p. 1-11. DOI:https://doi.org/10.1016/j.ijthermalsci.2020.106817.

2. Abele E, Altintas Y, Brecher C (2010). Machine tool spindle units. CIRP Annals. 59(2): p. 781-802. DOI:https://doi.org/10.1016/j.cirp.2010.05.002.

3. Cao H, Zhang X, Chen X (2017). The concept and progress of intelligent spindles: A review. International Journal of Machine Tools and Manufacture. 112: p. 21-52. DOI:https://doi.org/10.1016/j.ijmachtools.2016.10.005.

4. Ma C, Yang J, Zhao L, Mei X, Shi H (2015). Simulation and experimental study on the thermally induced deformations of high-speed spindle system. Applied Thermal Engineering. 86: p. 251-268. DOI:https://doi.org/10.1016/j.applthermaleng.2015.04.064.

5. Liu J, Ma C, Wang S, Wang S, Yang B, Shi H (2019). Thermal-structure interaction characteristics of a highspeed spindle- bearing system. International Journal of Machine Tools and Manufacture. 137: p. 42-57. DOI: https://doi.org/10.1016/j.ijmachtools.2018.10.004.

6. Zhang L, Li C, Wu Y, Zhang K, Shi H (2017). Hybrid Prediction Model of the Temperature Field of a Motorized 
Spindle. Applied Sciences. 7(10): p. 1091-1104. DOI:https://doi.org/10.3390/app7101091.

7. Tan F, Yin Q, Dong G, Xie L, Yin G (2017). An optimal convective heat transfer coefficient calculation method in thermal analysis of spindle system. The International Journal of Advanced Manufacturing Technology. 91(5-8): p. 2549-2560. DOI:https://doi.org/10.1007/s00170-016-9924-2.

8. Blaser P, Pavliček F, Mori K, Mayr J, Weikert S, Wegener K (2017). Adaptive learning control for thermal error compensation of 5-axis machine tools. Journal of Manufacturing Systems. 44: p. 302-309. DOI:https://doi.org/10.1016/j.jmsy.2017.04.011.

9. Ma C, Zhao L, Mei X, Shi H, Yang J (2016). Thermal error compensation of high-speed spindle system based on a modified BP neural network. The International Journal of Advanced Manufacturing Technology. 89(9-12): $\mathrm{p}$. 3071-3085. DOI:https://doi.org/10.1007/s00170-016-9254-4.

10. Grama S N, Mathur A, Badhe AN (2018). A model-based cooling strategy for motorized spindle to reduce thermal errors. International Journal of Machine Tools and Manufacture. 132: p. 3-16. DOI:https://doi.org/10.1016/j.ijmachtools.2018.04.004.

11. Liu T, Gao W, Zhang D, Zhang Y, Chang W, Liang C, Tian Y (2017). Analytical modeling for thermal errors of motorized spindle unit. International Journal of Machine Tools and Manufacture. 112: p. 53-70. DOI:https://doi.org/10.1016/j.ijmachtools.2016.09.008.

12. Zheng D-x, Chen W, Li M (2018). An improved model on forecasting temperature rise of high-speed angular contact ball bearings considering structural constraints. Industrial Lubrication and Tribology. 70(1): p. 15-22. DOI:https://doi.org/10.1108/ilt-06-2016-0133.

13. Liu J, Lai T, Tie G (2018). Influence of thermo-mechanical coupled behaviors on milling stability of high speed motorized spindles. Precision Engineering. 52: p. 94-105. DOI:https://doi.org/10.1016/j.precisioneng.2017.11.011.

14. Zheng D, Chen W (2017). Thermal performances on angular contact ball bearing of high-speed spindle considering structural constraints under oil-air lubrication. Tribology International. 109: p. 593-601. DOI:https://doi.org/10.1016/j.triboint.2017.01.035.

15. Liu J, Zhang P (2018). Thermo-mechanical behavior analysis of motorized spindle based on a coupled model. Advances in Mechanical Engineering. 10(1): p. 1-12. DOI:https://doi.org/10.1177/1687814017747144.

16. Wu L, Tan Q (2016). Thermal Characteristic Analysis and Experimental Study of a Spindle-Bearing System. Entropy. 18(7): p. 271-295. DOI:https://doi.org/10.3390/e18070271.

17. Lee J, Kim D-H, Lee C-M (2015). A study on the thermal characteristics and experiments of High-Speed spindle for machine tools. International Journal of Precision Engineering and Manufacturing. 16(2): p. 293-299. DOI:https://doi.org/10.1007/s12541-015-0039-8.

18. Sun L, Ren M, Hong H, Yin Y (2016). Thermal error reduction based on thermodynamics structure optimization method for an ultra-precision machine tool. The International Journal of Advanced Manufacturing Technology. 88(5-8): p. 1267-1277. DOI:https://doi.org/10.1007/s00170-016-8868-x.

19. Liu J, Ma C, Wang S, Wang S, Yang B (2019). Thermal contact resistance between bearing inner ring and shaft journal. International Journal of Thermal Sciences. 138: p. 521-535. DOI:https://doi.org/10.1016/j.ijthermalsci.2019.01.022.

20. Cui Y, Li H, Li T, Chen L (2018). An accurate thermal performance modeling and simulation method for motorized spindle of machine tool based on thermal contact resistance analysis. The International Journal of Advanced Manufacturing Technology. 96(5-8): p. 2525-2537. DOI:https://doi.org/10.1007/s00170-018-1593-x.

21. Yüncü H (2006). Thermal contact conductance of nominaly flat surfaces. Heat and Mass Transfer. 43(1): p. 1-5. DOI:https://doi.org/10.1007/s00231-006-0087-9.

22. Ji J, Hong R, Sun F, Huang X (2018). Thermal characteristic analysis of Z-axis guideway based on thermal contact resistance. Advances in Mechanical Engineering. 10(10): p. 1-14. 


\section{DOI:https://doi.org/10.1177/1687814018805321.}

23. Tanaka C B, Ballester R Y, De Souza G M, Zhang Y, Meira J B C (2019). Influence of residual thermal stresses on the edge chipping resistance of PFM and veneered zirconia structures: Experimental and FEA study. Dental Materials. 35(2): p. 344-355. DOI:https://doi.org/10.1016/j.dental.2018.11.034.

24. Song H, Vakis A I, Liu X, Van der Giessen E (2017). Statistical model of rough surface contact accounting for size-dependent plasticity and asperity interaction. Journal of the Mechanics and Physics of Solids. 106: p. 1-14. DOI:https://doi.org/10.1016/j.jmps.2017.05.014.

25. Xiao H, Sun Y (2019). On the normal contact stiffness and contact resonance frequency of rough surface contact based on asperity micro-contact statistical models. European Journal of Mechanics - A/Solids. 75: p. 450-460. DOI:https://doi.org/10.1016/j.euromechsol.2019.03.004.

26. Liu Y, Wang Y, Chen X, Yu H (2018). A spherical conformal contact model considering frictional and microscopic factors based on fractal theory. Chaos, Solitons \& Fractals. 111: p. 96-107. DOI:https://doi.org/10.1016/j.chaos.2018.04.017.

27. Gao Z, Fu W, Wang W, Kang W, Liu Y (2018). The study of anisotropic rough surfaces contact considering lateral contact and interaction between asperities. Tribology International. 126: p. 270-282. DOI:https://doi.org/10.1016/j.triboint.2018.01.056.

28. Wen Y, Tang J, Zhou W, Zhu C (2018). An improved simplified model of rough surface profile. Tribology International. 125: p. 75-84. DOI:https://doi.org/10.1016/j.triboint.2018.04.025.

29. Qin W, Jin X, Kirk A, Shipway P H, Sun W (2018). Effects of surface roughness on local friction and temperature distributions in a steel-on-steel fretting contact. Tribology International. 120: p. 350-357. DOI:https://doi.org/10.1016/j.triboint.2018.01.016.

30. Greenwood J A, Williamson J B P P (1966). Contact of nominally flat surfaces. Proceedings of the Royal Society of London. 295(1442): p. 300-319. DOI: https://doi.org/10.1098/rspa.1966.0242.

31. Kogut L, Etsion I (2002). Elastic-Plastic Contact Analysis of a Sphere and a Rigid Flat. Journal of Applied Mechanics. 69(5): p. 657-662. DOI:https://doi.org/10.1115/1.1490373

32. Lin L P, Lin J F (2005). An elastoplastic microasperity contact model for metallic materials. Journal of Tribology. 127(3): p. 666-672.

33. Zhao Y, Maietta D M, Chang L (1999). An Asperity Microcontact Model Incorporating the Transition From Elastic Deformation to Fully Plastic Flow. Journal of Tribology. 122(1): p. 86-93. DOI:https://doi.org/10.1115/1.555332.

34. Zheng D, Chen W, Zheng D (2021). An enhanced estimation on heat generation of angular contact ball bearings with vibration effect. International Journal of Thermal Sciences. 159: p. 106610. DOI:https://doi.org/10.1016/j.ijthermalsci.2020.106610.

35. Kiselev N A, Leontiev A I, Vinogradov Y A, Zditovets A G, Strongin M M (2019). Effect of large-scale vortex induced by a cylinder on the drag and heat transfer coefficients of smooth and dimpled surfaces. International Journal of Thermal Sciences. 136: p. 396-409. DOI:https://doi.org/10.1016/j.ijthermalsci.2018.11.005.

36. Xian Y, Zhang P, Zhai S, Yuan P, Yang D (2018). Experimental characterization methods for thermal contact resistance: A review. Applied Thermal Engineering. 130: p. 1530-1548. DOI:https://doi.org/10.1016/j.applthermaleng.2017.10.163. 